\title{
Endostar blocks the metastasis, invasion and angiogenesis of ovarian cancer cells
}

\author{
Y. DING*, Y. WANG, J. CUI, T. SI \\ Second Department of Gynecologic Oncology, Gansu Provincial Cancer Hospital, Lanzhou, China \\ ${ }^{*}$ Correspondence: dyan_yding@163.com
}

Received July 16, 2019 / Accepted October 8, 2019

\begin{abstract}
Endostar (ES) inhibits metastasis in some tumors, but its role in ovarian cancer invasion has not been elucidated. In this study, the effects of ES on ovarian cancer cells were further analyzed, to excavate an effective strategy for treating ovarian cancer. Ovarian cancer cell lines (SKOV3 and HO-8910PM) were treated with different concentrations of ES. Cell activity and half-maximal inhibitory concentration (IC50) detected by MTT were used for subsequent experiments. The migration and invasion abilities of treated cells were detected by wound healing and Transwell assays. The expressions of epithelialmesenchymal transition (EMT)-related proteins in treated cells were determined by western blot analysis. Moreover, in vitro angiogenesis, the expressions of related proteins in treated cells and STAT3, and PD-L1 expressions were determined. We found that with the increase of ES concentrations, the cell activity showed a decreasing trend, and that the compositive IC50 of SKOV3 and HO-8910PM was $50 \mu \mathrm{g} / \mathrm{ml}$. Moreover, ES observably inhibited migration, invasion, and EMT of ovarian cancer cell lines. In angiogenesis experiments, the angiogenesis ability and the expressions of related proteins in ovarian cancer cell lines were downregulated after ES treatment. Furthermore, ES reduced the expression of PD-L1 and suppressed the phosphorylation of STAT3 in ovarian cancer cell lines. ES blocked the metastasis, invasion, and angiogenesis of ovarian cancer cells by suppressing the activation of PD-L1 and STAT3, which might be considered as the potential mechanism of ES in the treatment of ovarian cancer.
\end{abstract}

Key words: endostar, ovarian cancer, migration, invasion, angiogenesis

Ovarian cancer is one of the most frequent malignant tumors in the female reproductive system, with a 5-year survival rate of less than $45 \%$ [1]. As early symptoms of ovarian cancer are not obvious, most patients are diagnosed at an advanced stage, accompanied with the occurrence of infiltration and metastasis that seriously affects the prognosis of patients [2]. Although progress has been continuously made in surgery, chemotherapy and other treatments, the 5-year survival rate of patients with ovarian cancer has improved slightly [3]. Compared with normal tissues, tumor vasculature is characterized by structural disorders, insufficient blood supply, and enhanced vascular permeability. The growth and spread of tumors rely on the blood supply of surrounding tissues, thus leading to decreased efficiency of cytotoxic chemotherapeutic drugs and increased risk of metastasis. In recent years, it has been found that angiogenesis and vascular normalization play a crucial role in tumor growth, invasion, and migration [4]. With the continuous advances in tumor angiogenesis research and the synthesis of various antiangiogenic drugs, anti-angiogenesis therapy has attracted much research attention in the treatment of tumors [5].
Endostar (ES), a multi-target vascular endothelial inhibitor, can reduce tumor angiogenesis through blocking the migration of endothelial cells and interrupting the nutritional supply of tumor cells by acting on the microenvironment, so as to inhibit the proliferation or metastasis of tumor cells and postpone the progress of tumors [6]. In the early years, ES combined with vinorelbine/cisplatin was approved by China Food and Drug Administration (CFDA) for the treatment of patients with advanced non-small cell lung cancer (NSCLC), and therefore, ES has become the standard firstline therapy for NSCLC in China [7]. It has been reported that ES could inhibit the invasion, migration, and epithelialmesenchymal transition (EMT) of lung carcinoma cells in vitro through interdicting the activation of the MMP family [8]. Jin et al. [9] pointed out that ES effectively improved the prognosis of patients with metastatic nasopharyngeal cancer and patients showed a better tolerance. Moreover, in female tumors, researchers have reported that ES in combination with chemotherapy was effective and safe in the treatment of patients with HER-2-negative metastatic breast cancer [10]. Thus, it was proved that ES has been widely used in the field 
of cancers and has positive results in the treatment of tumor metastasis and invasion.

However, a limited number of studies were conducted on the role and mechanism of ES in ovarian cancer invasion and metastasis, thus, in vitro, the current study applied ES to the treatment of ovarian cancer cell lines, and further analyzed the effects of ES on cell migration, invasion, and angiogenesis, so as to excavate an effective treatment for ovarian cancer and improve the survival rate of patients.

\section{Materials and methods}

Cell culture. Ovarian cancer cell lines (SKOV3 and HO-8910PM) were purchased from the Type Culture Collection Centre of the Chinese Academic of Science (Shanghai, China). The cells were incubated in Dulbecco's modified Eagle's medium (DMEM; Gibco, Thermo Fisher Scientific, Inc., Waltham, MA, USA) supplemented with $10 \%$ fetal bovine serum (FBS; Gibco, USA), $100 \mathrm{U} / \mathrm{ml}$ penicillin and $100 \mu \mathrm{g} / \mathrm{ml}$ streptomycin (Gibco, USA) at $37^{\circ} \mathrm{C}$ with $5 \% \mathrm{CO}_{2}$. Logarithmic phase cells were collected for the following experiments.

Cell viability. Ovarian cancer cell lines were seeded into 96-well plates $\left(2 \times 10^{3}\right.$ cells/well $)$ and treated by ES at different concentration $(0.01 ; 0.1 ; 1 ; 10 ; 100 \mu \mathrm{g} / \mathrm{ml})$, respectively, while untreated cells served as blank controls. After treatment for 72 h, 3-(4),-5-dimethylthiazole-2-acyl)-2, 5-diphenyltetrazole ammonium bromide (MTT) assay was performed for the detection of cell viability. Briefly, $10 \mu \mathrm{l}$ MTT reagent (Sigma, USA) was added into the cells in the dark at $37^{\circ} \mathrm{C}$ for $4 \mathrm{~h}$, and the optical density (OD) value of each well at $490 \mathrm{~nm}$ was measured using the ELX-800 Biotek plate reader (Winooski, USA). Moreover, half-maximal inhibitory concentration (IC50) was calculated, and the compositive IC50 of cells was used as the experimental concentration for the subsequent experiments.

Wound healing assay. The migration ability of ovarian cancer cell lines was detected by wound healing assay. For the detection, wounds were scratched at the bottom of the plates using a $200 \mu$ l pipette tip. Untreated cells and cells $(3 \times$ $10^{4} /$ well) treated by ES at IC50, respectively were cultivated in serum-free medium for $24 \mathrm{~h}$. The relative migration rate of cells was observed and quantified under the Nikon Eclipse TS-100 inverted microscope.

Transwell assay. A 24-well Transwell chamber (Corning, MA, USA) was used to determine the invasion of ovarian cancer cell lines. In brief, upper chambers were pre-coated with matrigel (BD Bioscience, CA, USA) for performing the invasion assay, while cells (approximately $1 \times 10^{5}$ cells) untreated or treated with ES were transferred onto the upper chambers. After treatment for $24 \mathrm{~h}$, the cells were fixed by methanol and dyed by $0.1 \%$ crystal violet solution for $15 \mathrm{~min}$. Cell invasion was observed under an inverted microscope.

In vitro angiogenesis experiment. The angiogenesis ability of ovarian cancer cell lines was detected by the in vitro angiogenesis experiment. For the experiment, 96-well plates were pre-covered by $50 \mu$ l Matrigel $^{\mathrm{TM}}$ Matrix collagen (BD Biosciences, USA) for $1 \mathrm{~h}$ at $37^{\circ} \mathrm{C}$. Untreated cells $\left(4 \times 10^{4}\right.$ cells/well) or cells treated by ES were cultivated in the plates at $37^{\circ} \mathrm{C}$ with $5 \% \mathrm{CO}_{2}$. After $24 \mathrm{~h}, 4 \%$ paraformaldehyde was used to fix the cells for $15 \mathrm{~min}$ at $37^{\circ} \mathrm{C}$. The tubular structures of cells were obtained by the CCX7C1115 Thermo Fisher Scientific Cellomics (Waltham, MA, USA), and Image software (National Institutes of Health (NIH), Bethesda, MD, USA) was used for quantitative analysis.

Quantitative real-time polymerase chain reaction (qRT-PCR) assay. qRT-PCR assay was performed to measure the expressions of angiogenesis-related proteins in ovarian cancer cell lines. Total RNA of cells was separated using the Trizol reagent (Invitrogen, Carlsbad, California, USA). The purity and concentration of separated RNA were further verified by the spectrophotometer (NanoDrop2000c, Thermo Fisher Scientific, Massachusetts, USA), and the integrity was measured using $1 \%$ agarose modified gel electrophoresis. $1 \mu \mathrm{g}$ total RNA was used to reversetranscribe and synthesize cDNA by PrimeScript RT Master Mix Perfect Real Time (TaKaRa, Shiga, Japan). The synthesized cDNA was used for qRT-PCR assay by LightCycler ${ }^{\oplus}$ 480 SYBR Green I Master Mix (Roche, Germany) under the following conditions: 35 cycles of $5 \mathrm{~min}$ at $95^{\circ} \mathrm{C}, 30 \mathrm{~s}$ at $95^{\circ} \mathrm{C}, 30 \mathrm{~s}$ at $61^{\circ} \mathrm{C}$, and $60 \mathrm{~s}$ at $72^{\circ} \mathrm{C}$, followed by a final extension for $5 \mathrm{~min}$ at $72^{\circ} \mathrm{C}$. The sequences of primers used for qRT-PCR assay were shown in Table 1 and synthesized by Gene Pharma (Shanghai, China). GAPDH served as the internal reference, and $2^{-\triangle \Delta C T}$ method [11] was adopted to determine the relative expression level of mRNA.

Western blot (WB) analysis. WB assay was performed to measure the expressions of related proteins in ovarian cancer cell lines. Total proteins of the cells were extracted using RIPA buffer (Solarbio, Beijing, China), and quantitated by the Bicinchoninic Protein Assay kit (BCA, Pierce, Rockford, IL, USA). Total protein $(50 \mu \mathrm{g})$ was separated on sodium dodecyl sulfate polyacrylamide gel electrophoresis (SDS-PAGE, Beyotime, Shanghai, China), and transferred

Table 1. The sequences of primers.

\begin{tabular}{lll}
\hline Gene & Forward (5'-3') & Reverse (5'-3') \\
\hline EGFR & GCCAAGGCACGAGTAACAAGC & AGGGCAATGAGGACATAACCAG \\
bFGF & CGGTGTGCCTGTGGAGGAACTT & GTTACAGCTGACGGTGGAGTCT \\
ANG1 & GCGGATCCATGACAGTTTTCCTTTCCTTTG & CGGCTCGAGAAAATCTAAAGGTCGAATCATC \\
GAPDH & AGAAGGTGGTGAAGCAGGCATC & CGAAGGTGGAAGAGTGCGAGTTG \\
\hline
\end{tabular}


onto the polyvinylidene fluoride (PVDF) membrane. Then, the membrane was sealed by $5 \%$ non-fat dried milk for 2 $\mathrm{h}$, and incubated with the primary antibodies EMT-related proteins (E-Cadherin $(1: 1000$, \#14472, Cell Signaling Technology, USA), N-Cadherin (1:1000, \#14215, Cell Signaling Technology, USA), Vimentin (1:1000, ab92547, Abcam, USA), Snail (2 $\mu \mathrm{g} / \mathrm{ml}$, ab53519, Abcam, USA), MMP2 (2 $\mu \mathrm{g} / \mathrm{ml}, \mathrm{ab} 37150$, Abcam, USA) and MMP3 (1:1000, ab52915, Abcam, USA)), angiogenesis-related proteins (EGFR (1:1000, ab52894, Abcam, USA), bFGF (0.5 $\mu \mathrm{g}, \mathrm{ab} 126861$, Abcam, USA), ANG1 (1:500, ab8451, Abcam, USA), PD-L1 ( $2 \mu \mathrm{g} / \mathrm{ml}$, ab205921, Abcam, USA), p-STAT3 (1:2000, \#9145, Cell Signaling Technology, USA), STAT3 (1:2000, \#4904, Cell Signaling Technology, USA)) overnight at $4{ }^{\circ} \mathrm{C}$. GAPDH (1:1000, ab8245, Abcam, USA) served as the internal reference. Subsequently, the homologous secondary antibodies goat anti-rabbit IgG H\&L (HRP, 1:7000, ab97051, Abcam, USA), goat anti-mouse IgG H\&L (HRP, 1:1000, ab150113, Abcam), and donkey anti-goat IgG H\&L (HRP, $1: 2000$, ab205723, Abcam) were used to incubate with the membrane at room temperature for another $1 \mathrm{~h}$. The bands were developed using an enhanced chemiluminescencedetecting kit (Thermo Fisher, MA, USA).

Statistical analysis. Statistical Package for the Social Sciences version 20.0 (SPSS, Inc.,Chicago, USA) software was used for data analysis, and the data were shown as mean \pm standard deviation (SD). The comparison between groups was performed by Student's t-test or one-way analysis of variance (ANOVA). All experiments were repeated in triplicate. $\mathrm{p}<0.05$ was considered as statistically significant.

\section{Results}

ES suppressed the activity, migration, and invasion of ovarian cancer cell lines. The results of MTT experiments showed that ES at the concentrations of $0.1 ; 1 ; 10$; $100 \mu \mathrm{g} / \mathrm{ml}$ observably inhibited the viabilities of SKOV3 and HO-8910PM cells, and that the inhibitory ability of ES was enhanced with the increase of drug concentration $(\mathrm{p}<0.05$; Figure 1). In addition, the analysis by SPSS software calculated that the IC50 of SKOV3 cell was $49.77 \mu \mathrm{g} / \mathrm{ml}$ and that of HO-8910PM was $51.47 \mu \mathrm{g} / \mathrm{ml}$. The compositive IC50 $(50 \mu \mathrm{g} / \mathrm{ml})$ was used as test concentration in the follow-up experiments in order to further explore the effects of ES on the invasion and metastasis of ovarian cancer cell lines. Wound healing assay revealed that ES obviously shortened the migration distances of SKOV3 and HO-8910PM cells and Transwell tests also observed that ES inhibited cell invasion $(\mathrm{p}<0.001$; Figure 2). Furthermore, in epithelial-mesenchymal transition (EMT)-related proteins, WB analysis determined that ES visibly increased the expression of E-Cadherin in ovarian cancer cell lines, while it downregulated the expression levels of N-Cadherin, Vimentin, Snail, MMP2, and MMP3 ( $\mathrm{p}<0.001$; Figures 3A, 3B).

ES reduced the angiogenesis of ovarian cancer cell lines and suppressed the expressions of PD-L1 and p-STAT3. In vitro angiogenesis experiments observed that ES clearly reduced the angiogenesis of SKOV3 and HO-8910PM cells compared with blank controls ( $\mathrm{p}<0.05$; Figures $3 \mathrm{C}, 3 \mathrm{D})$ ). For confirmation, qRT-PCR and WB assays were carried out to detect the expressions of angiogenesis-related proteins and mRNAs in SKOV3 and HO-8910PM cells and the results demonstrated that ES overtly decreased the expressions of EGFR, bFGF, and ANG1 ( $<<0.001$; Figure 4). Moreover, WB assay also showed that ES had the function of suppressing the expressions of PD-L1 and p-STAT3 in ovarian cancer cell lines, accordingly, the ratios of p-STAT3/STAT3 in SKOV3 and $\mathrm{HO}-8910 \mathrm{PM}$ cells were observably downregulated with the addition of $E S$ ( $p<0.001$; Figure 5).

\section{Discussion}

The biological behavior of ovarian cancer is complex. $70 \%$ of patients have been diagnosed as having middle or advanced stage ovarian cancer at their first diagnosis, due to the atypical early symptoms of the disease, and the
A

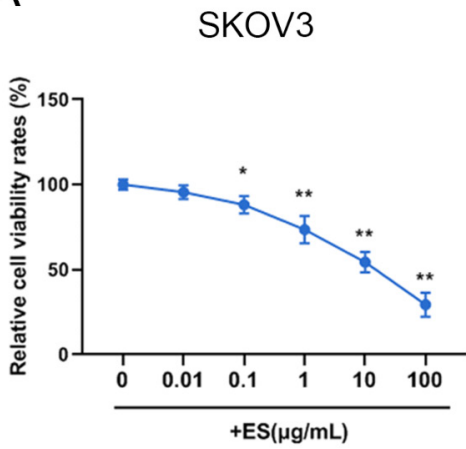

B

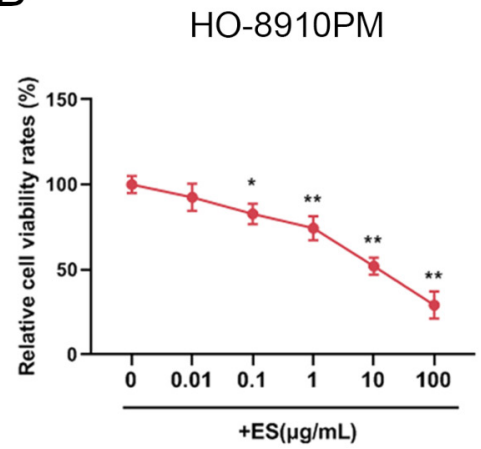

Figure 1. Endostar (ES) suppressed the viability of ovarian cancer cell lines. 3-(4),-5-dimethylthiazole-2-acyl)-2, 5-diphenyltetrazole ammonium bromide (MTT) assay was performed to detect the viability rates of (A) SKOV3 and (B) HO-8910PM cells after treatment with ES at different concentrations $(0 ; 0.01 ; 0.1 ; 1 ; 10 ; 100 \mu \mathrm{g} / \mathrm{ml}) .{ }^{*} \mathrm{p}<0.05,{ }^{* *} \mathrm{p}<0.001, \mathrm{vs.} 0 ; \mathrm{n}=3$ 
A
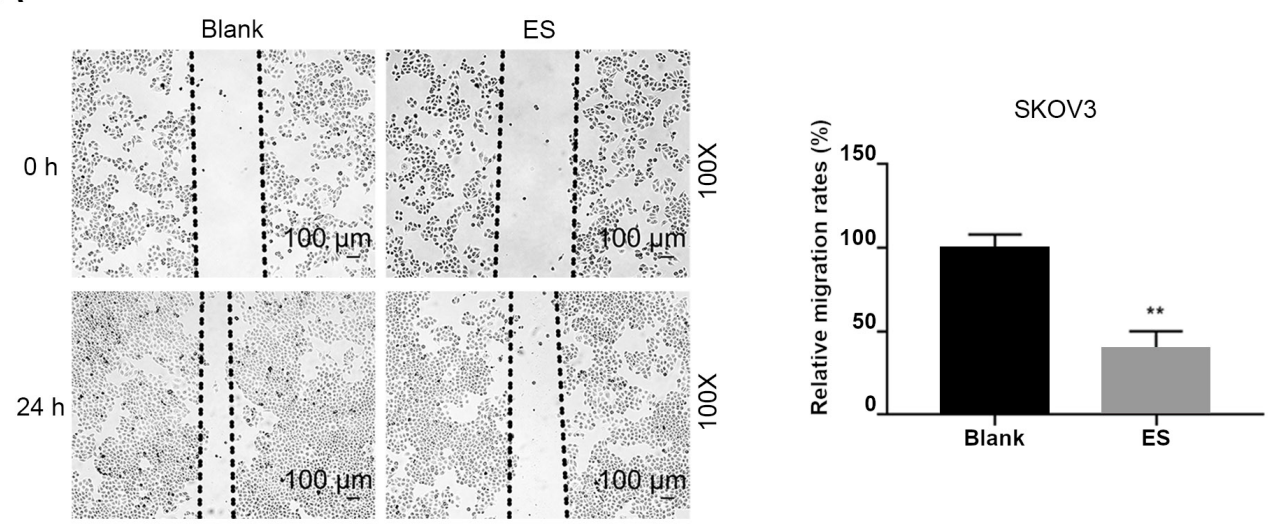

B
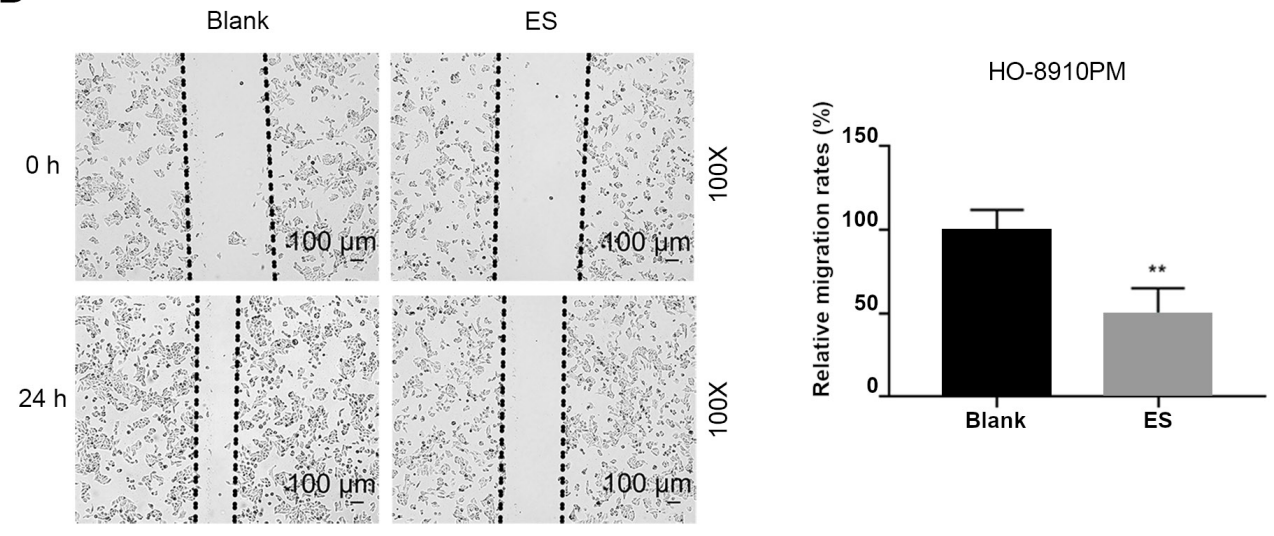

C
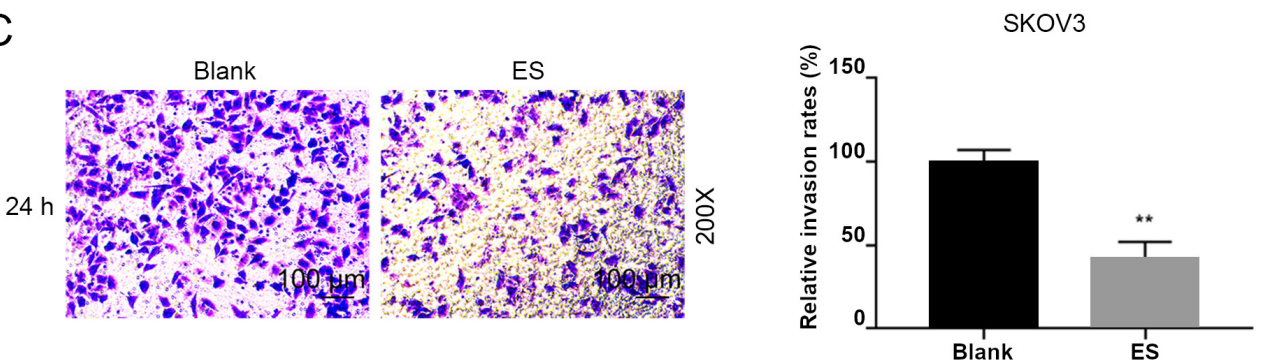

$\mathrm{D}$
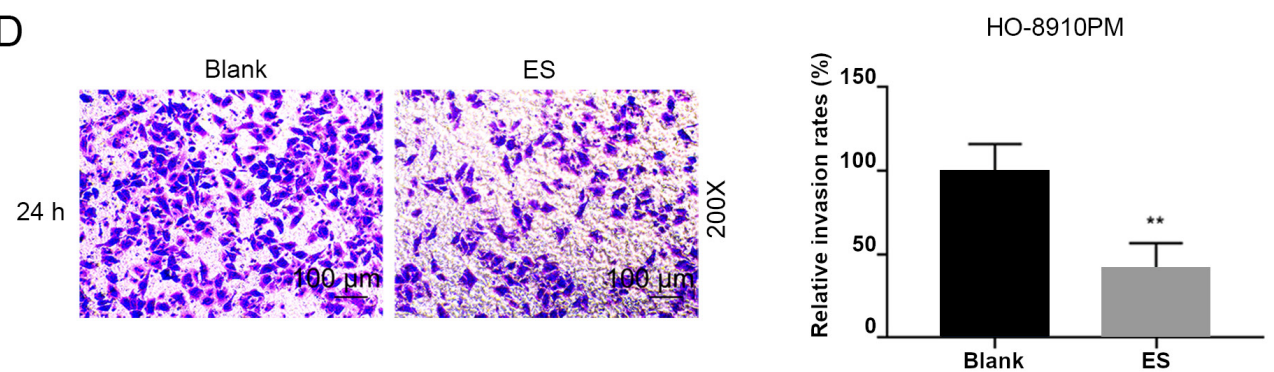

Figure 2. Endostar (ES) suppressed the migration and invasion of ovarian cancer cell lines. Microscopic pictures and quantitative analysis of wound healing assays in (A) SKOV3 and (B) HO-8910PM cells. Microscopic pictures and quantitative analysis of Transwell tests in (C) SKOV3 and (D) HO8910PM cells. Ovarian cancer cell lines were treated with ES of $50 \mu \mathrm{g} / \mathrm{ml}$. Untreated cells were taken as the blank controls. ${ }^{* *} \mathrm{p}<0.001$, vs. blank; $\mathrm{n}=3$ 
A

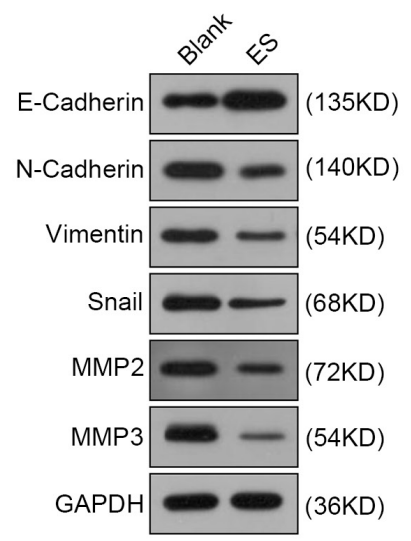

B

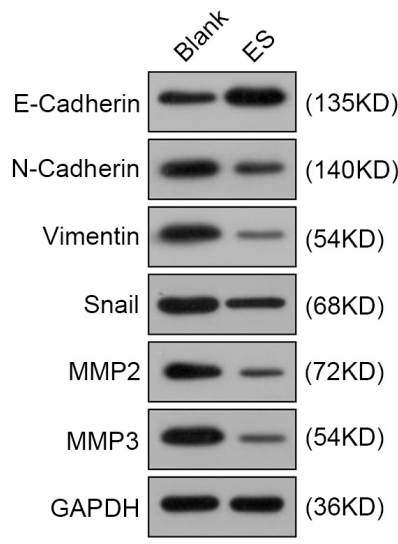

C

$\mathrm{D}$
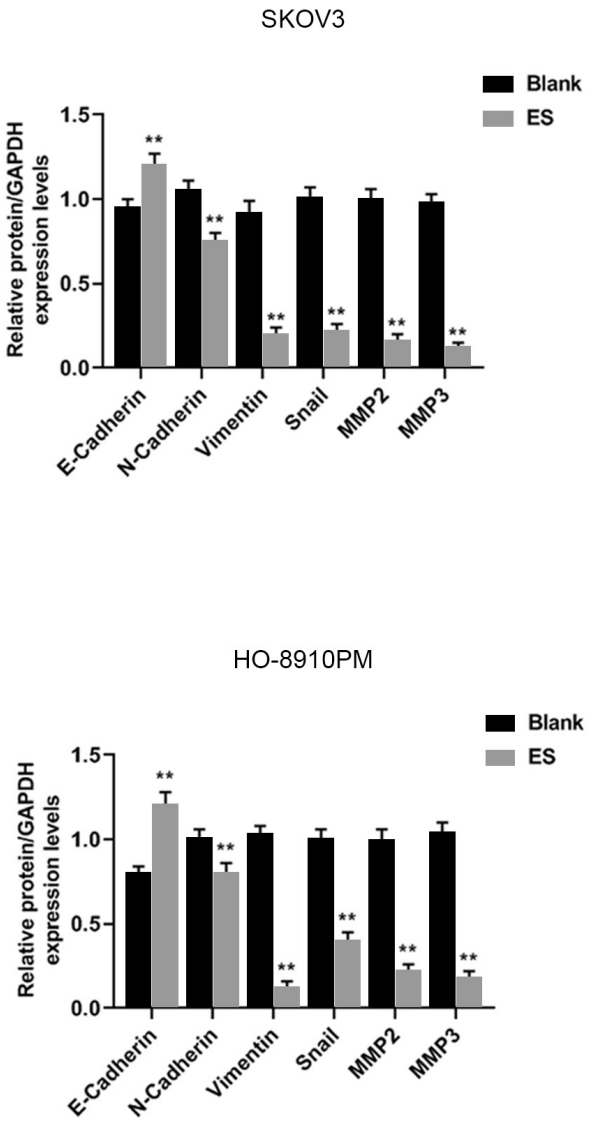
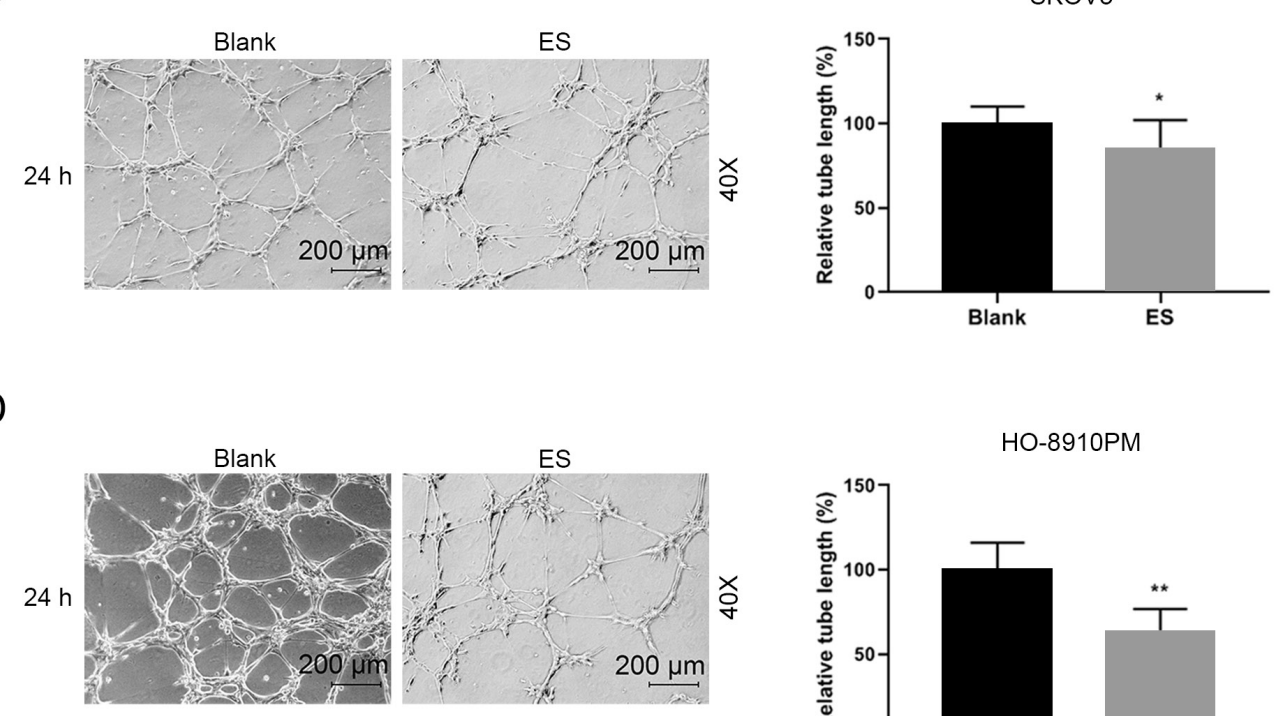

HO-8910PM

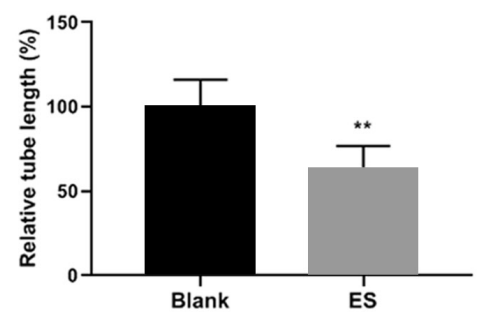

Figure 3. Endostar (ES) reduced the angiogenesis of ovarian cancer cell lines. WB analysis determined the expressions of epithelial-mesenchymal transition (EMT)-related proteins (E-Cadherin, N-Cadherin, Vimentin, Snail, MMP2, and MMP3) in (A) SKOV3 and (B) HO-8910PM cells. (C, D) The angiogenesis abilities of (C) SKOV3 and (D) HO-8910PM cells were detected by the in vitro angiogenesis experiments. Ovarian cancer cell lines were treated with ES of $50 \mu \mathrm{g} / \mathrm{ml}$. Untreated cells served as the blank controls. ${ }^{*} \mathrm{p}<0.05,{ }^{* *} \mathrm{p}<0.001$, vs. blank; $\mathrm{n}=3$ 
A

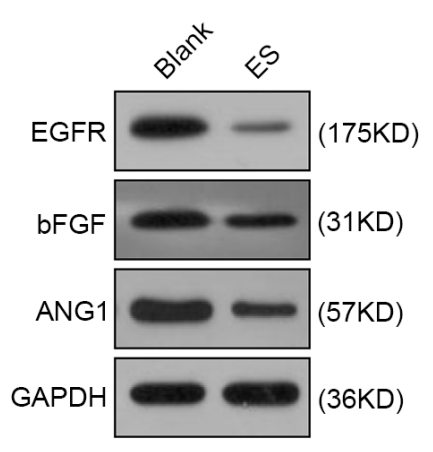

D

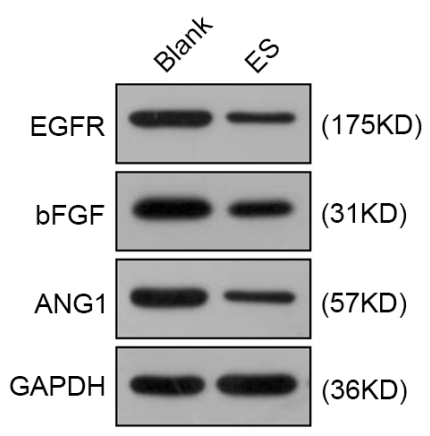

B

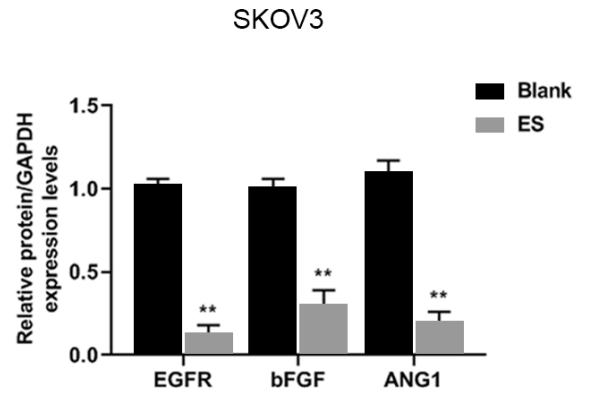

E

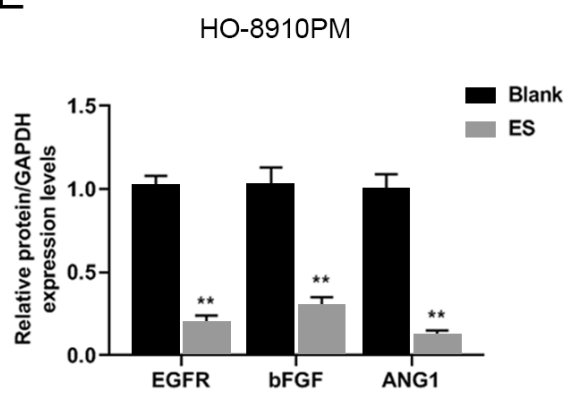

C

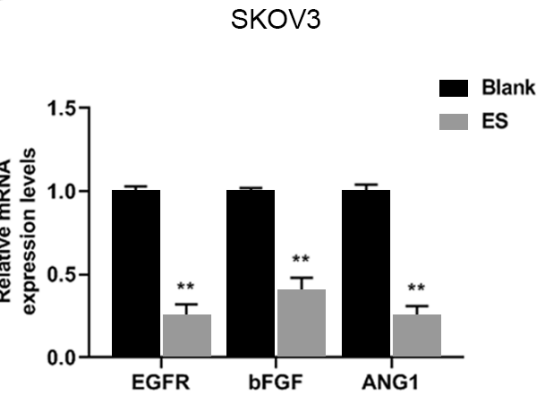

$\mathrm{F}$

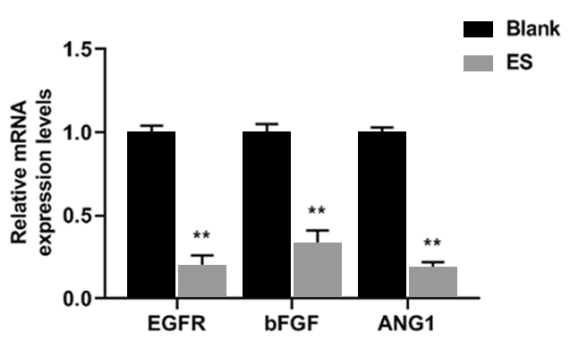

Figure 4. Endostar (ES) downregulated the expressions of angiogenesis-related proteins in ovarian cancer cell lines. WB analysis and quantitative real-time polymerase chain reaction (qRT-PCR) assays measured the expressions of angiogenesis-related proteins and mRNAs (EGFR, bFGF, ANG1) in (A-C) SKOV3 and (D-F) HO-8910PM cells. Ovarian cancer cell lines were treated with ES of $50 \mu \mathrm{g} / \mathrm{ml}$. Untreated cells served as the blank controls. ${ }^{* *} \mathrm{p}<0.001$, vs. blank; $\mathrm{n}=3$

5 -year survival rate of ovarian cancer patients is still low, even after they had received surgery and chemotherapy [12]. Anatomically, ovaries are deeply embedded in the pelvic cavity, which allows ovarian cancer cells to directly spread to adjacent organs and implant into the visceral peritoneum or parietal peritoneum. Therefore, how to inhibit the invasion and metastasis of cancer cells has attracted much research attention and become a difficulty in the clinical treatment of ovarian cancer. EMT, which is a critical mechanism of tumor metastasis, refers to the biological process of epithelial cells transforming into mesenchymal cells [13]. EMT is characterized by the decrease or loss of a generation of epithelial markers such as E-Cadherin, while, at the same time, the expressions of mesenchymal phenotypic markers $\mathrm{N}$-Cadherin and Vimentin are increased. E-cadherin is an important factor mediating intercellular adhesion and its loss is an initial sign indicating tumor cell invasion and metastasis [14]. The abnormal expressions of N-Cadherin and Vimentin often accelerate EMT and increase the motility and invasiveness of cancer cells [15], moreover, Snail, which is another key factor in the occurrence of EMT, can inhibit the expression of E-Cadherin via binding to its promoter [16]. In EMT transformation, extracellular matrix (ECM), which is mainly degraded by matrix metalloproteinases (MMPs), has the effect of promoting tumor invasion and metastasis, especially MMP2 and MMP3 [17]. The current study carried out the migration and invasion experiments and detected EMT-related proteins, so as to determine the action mechanism of experimental drugs.

In a previous study, ES inhibited the migration and invasion of lung cancer cells, and upregulated the expression levels of E-Cadherin and reduced the expressions of $\mathrm{N}$-Cadherin, Vimentin, and Snail, thus delaying the progression of lung cancer [6]. Consistently, this study also found that ES not only inhibited the migration and invasion of ovarian cancer cell lines but also upregulated E-Cadherin level, while the expressions of N-Cadherin, Vimentin, Snail, MMP2, and MMP3 were suppressed. These findings suggested that ES played an anti-tumor role in ovarian cancer through inhibiting the migration, invasion and EMT of cancer cells, thus improving the disease. Researchers also found that ES had an inhibitory effect on the invasion of human breast cancer cells by downregulating the expressions of MMP2 and MMP9 [18]. In other tumor fields, Gao et al. [19] discovered that ES could enhance the anti-tumor activity of fusion protein in liver cancer. Thus, these studies further confirmed the role of ES in inhibiting metastasis of malignant tumor cells. As for the action mechanism of ES, the target of ES is believed to be neovascular endothelial cells in tumors [20], as ES can enrich neovascularization in tumors and combine with the specific 
A

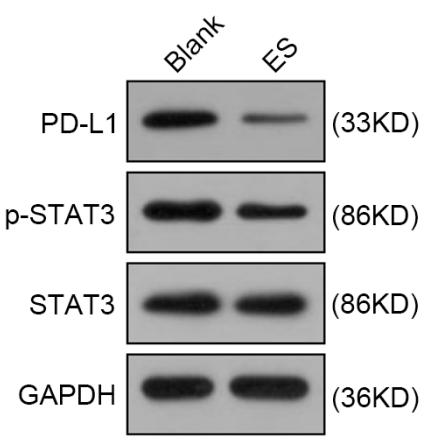

D

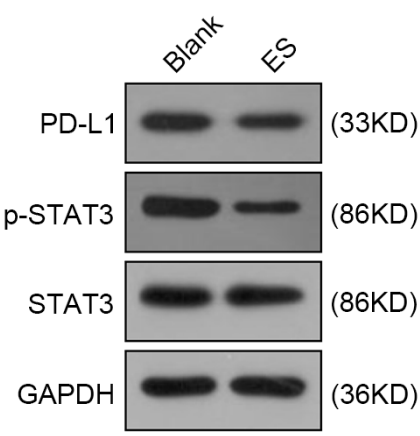

B

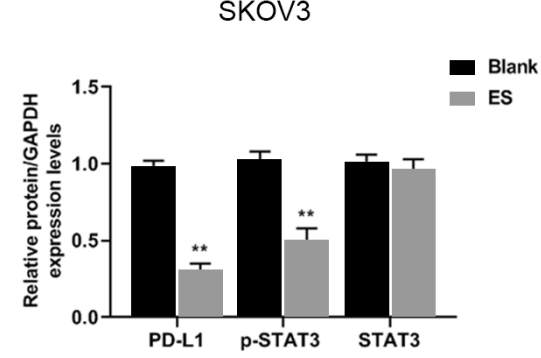

E

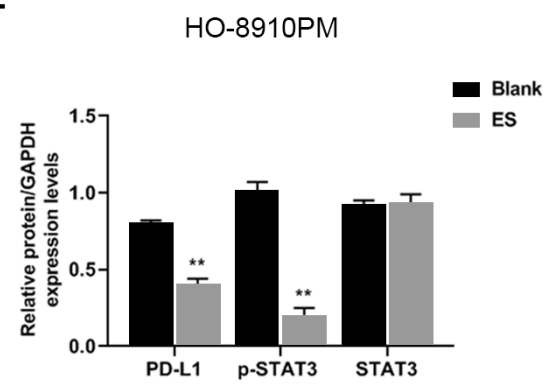

C

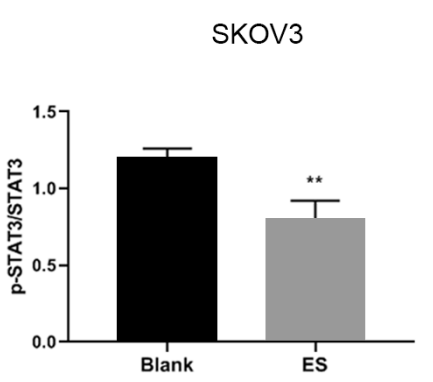

F
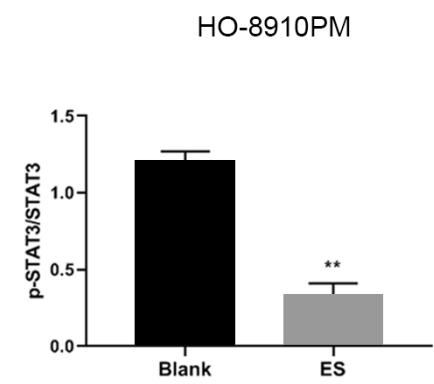

Figure 5. Endostar (ES) reduced the expressions of PD-L1 and p-STAT3 in ovarian cancer cell lines. WB assays analyzed the expressions of PD-L1, p-STAT3, and STAT3 in (A-C) SKOV3 and (D-F) HO-8910PM cells, and the ratio of p-STAT3/STAT3 was calculated. Ovarian cancer cell lines were treated with ES of $50 \mu \mathrm{g} / \mathrm{ml}$. Untreated cells served as the blank controls. ${ }^{* *} \mathrm{p}<0.001$, vs. blank; $\mathrm{n}=3$

targets on vascular endothelial cells, thus inducing apoptosis of vascular endothelial cells and destroying the formation of neovascularization. As a result, tumors lose the nutrition and oxygen supply of neovascularization, leading to the apoptosis of tumor cells, thereby reducing the invasion of tumors [21].

In the process of tumorigenesis, tumor cells can produce a large number of pro-angiogenic factors, such as EGFR, bFGF, ANG1, etc., among them, EGFR is considered as a key regulator in angiogenesis, with the strongest effect and highest specificity. Studies have shown that activated EGFR enhanced the invasive phenotype of ovarian cancer cells, suggesting that EGFR played a key role in the occurrence and development of ovarian cancer [22]. As a cytokinogen, bFGF has the function of promoting the growth and differentiation of various cells, especially endothelial cells. It has been proved that the reduction of bFGF could inhibit the proliferation and invasion of ovarian cancer cells [23]. ANG1 also can promote the development of new blood vessels and lymphatic vessels by binding to vascular receptor kinase, which may be related to neoplastic angiogenesis [24]. In this present study, on one hand, we observed that ES reduced the angiogenesis of ovarian cancer cell lines through in vitro angiogenesis experiments; on the other hand, we also found that ES significantly suppressed the expressions of angiogenesis-related factors, including EGFR, bFGF, and ANG1, in ovarian cancer cell lines. Thus, it could be speculated that ES might play an anti-metastatic role in ovarian cancer via inhibiting the angiogenesis and expressions of related factors.

In addition to the factors mentioned above, researchers indicated that PD-L1 and STAT3 also played a momentous role in EMT and tumor metastasis, such as in lung cancer [25] and colorectal cancer [26]. The activation of the PD-L1 signaling pathway can lead to the immunosuppression of tumor microenvironment so that tumor cells can escape from the body's immune surveillance and promote tumor metastasis [27]. A previous study demonstrated that PD-L1 was positively expressed in nearly $70 \%$ of ovarian cancer cases and was associated with poor prognosis [28]. STAT3 is an important member of signal transduction and transcriptional activator family, and p-STAT3 has been recognized as a carcinogenic factor. In early trials, Saini et al. [29] reported that STAT3 expression was abnormally increased in ovarian cancer ascites, which promoted the invasion, metastasis, and angiogenesis of tumors. In addition, Fujita et al. [30] indicated that STAT3 could promote tumor metastasis by increasing the expression of PD-L1. Liu et al. [31] showed that the inhibition of p-STAT3 reduced tumor-induced angiogenesis in head and neck cancer. The current study revealed that ES downregulated the expressions of PD-L1 and p-STAT3, suggesting that ES can inhibit the metastasis, angiogenesis, 
and EMT of ovarian cancer cells by blocking the activation of PD-L1 and STAT3, thus exerting its anti-tumor activity.

Previously, researchers have believed that OC metastasizes via a passive mechanism by which $\mathrm{OC}$ cells are shed from the primary tumor and carried by the physiological movement of peritoneal fluid to the peritoneum and omentum [32, 33]. Therefore, cell migration and adhesion could partially contribute to the OC metastasis. Recently, hematogenous metastasis of $\mathrm{OC}$ is an alternative route of metastasis that OC cells at the primary tumor site invade through the basal membrane of blood vessels and enter the circulation via intravasation $[2,34]$. So, the process of EMT and reduce tumor angiogenesis, which could also contribute to the OC metastasis.

Based on the reasons that both intraperitoneal dissemination and hematogenous spread of circulating tumor cells are possible mechanisms of OC metastasis, the current study demonstrated that ES blocked the metastasis, invasion, and angiogenesis of ovarian cancer cells by suppressing the activation of PD-L1 and STAT3, which might be the potential mechanism of ES in the treatment of ovarian cancer.

\section{References}

[1] WEBB PM, JORDAN SJ. Epidemiology of epithelial ovarian cancer. Best Pract Res Clin Obstet Gynaecol 2017; 41: 3-14. https://doi.org/10.1016/j.bpobgyn.2016.08.006

[2] YEUNG TL, LEUNG CS, YIP KP, AU YEUNG CL, WONG ST et al. Cellular and molecular processes in ovarian cancer metastasis. A Review in the Theme: Cell and Molecular Processes in Cancer Metastasis. Am J Physiol Cell Physiol 2015; 309: C444-56. https://doi.org/10.1152/ajpcell.00188.2015

[3] EISENHAUER EA. Real-world evidence in the treatment of ovarian cancer. Ann Oncol 2017; 28: viii61-viii65. https:// doi.org/10.1093/annonc/mdx443

[4] VIALLARD C, LARRIVEE B. Tumor angiogenesis and vascular normalization: alternative therapeutic targets. Angiogenesis 2017; 20: 409-426. https://doi.org/10.1007/s10456017-9562-9

[5] XIE L, JI T, GUO W. Anti-angiogenesis target therapy for advanced osteosarcoma (Review). Oncol Rep 2017; 38: 625636. https://doi.org/10.3892/or.2017.5735

[6] SHEN Y, CHEN Q, LI L. Endostar regulates EMT, migration and invasion of lung cancer cells through the HGFMet pathway. Mol Cell Probes 2019; 45: 57-64. https://doi. org/10.1016/j.mcp.2019.05.003

[7] AN J, LV W. Endostar (rh-endostatin) versus placebo in combination with vinorelbine plus cisplatin chemotherapy regimen in treatment of advanced non-small cell lung cancer: A meta-analysis. Thorac Cancer 2018; 9: 606-612. https://doi. org/10.1111/1759-7714.12626

[8] NI Q, JI H, ZHAO Z, FAN X, XU C. Endostar, a modified endostatin inhibits non small cell lung cancer cell in vitro invasion through osteopontin-related mechanism. Eur J Pharmacol 2009; 614: 1-6. https://doi.org/10.1016/j. ejphar.2009.04.032
[9] JIN T, JIANG F, JIN QF, PIAO YF, CHEN XZ. Endostar Combined with Gemcitabine and Cisplatin Chemotherapy for Patients with Metastatic Nasopharyngeal Carcinoma: an Update. Transl Oncol 2018; 11: 286-291. https://doi. org/10.1016/j.tranon.2018.01.002

[10] HUANG W, LIU J, WU F, CHEN K, LI N et al. The efficacy and safety of endostar combined with taxane-based regimens for HER-2-negative metastatic breast cancer patients. Oncotarget 2016; 7: 31501-31507. https://doi.org/10.18632/ oncotarget.8967

[11] RAO X, HUANG X, ZHOU Z, LIN X. An improvement of the $2^{\wedge}$ (-delta delta CT) method for quantitative real-time polymerase chain reaction data analysis. Biostat Bioinforma Biomath 2013; 3: 71-85.

[12] OBERAIGNER W, MINICOZZI P, BIELSKA-LASOTA M, ALLEMANI C, DE ANGELIS R et al. Survival for ovarian cancer in Europe: the across-country variation did not shrink in the past decade. Acta Oncol 2012; 51: 441-453. https://doi.org/10.3109/0284186X.2011.653437

[13] MARCUCCI F, STASSI G, DE MARIA R. Epithelial-mesenchymal transition: a new target in anticancer drug discovery. Nat Rev Drug Discov 2016; 15: 311-325. https://doi. org/10.1038/nrd.2015.13

[14] WONG SHM, FANG CM, CHUAH LH, LEONG CO, NGAI SC. E-cadherin: Its dysregulation in carcinogenesis and clinical implications. Crit Rev Oncol Hematol 2018; 121: 11-22. https://doi.org/10.1016/j.critrevonc.2017.11.010

[15] ZHANG X, LIU G, KANG Y, DONG Z, QIAN Q et al. Ncadherin expression is associated with acquisition of EMT phenotype and with enhanced invasion in erlotinib-resistant lung cancer cell lines. PLoS One 2013; 8: e57692. https://doi. org/10.1371/journal.pone.0057692

[16] BATlLE E, SANCHO E, FRANCI C, DOMINGUEZ D, MONFAR $M$ et al. The transcription factor snail is a repressor of E-cadherin gene expression in epithelial tumour cells. Nat Cell Biol 2000; 2: 84-89. https://doi.org/10.1038/35000034

[17] YANG H, LIANG J, ZHOU J, MI J, MA K et al. Knockdown of RHOC by shRNA suppresses invasion and migration of cholangiocellular carcinoma cells via inhibition of MMP2, MMP3, MMP9 and epithelial-mesenchymal transition. Mol Med Rep 2016; 13: 5255-5261. https://doi.org/10.3892/ mmr.2016.5170

[18] LU N, LING Y, GAO Y, CHEN Y, MU R et al. Endostar suppresses invasion through downregulating the expression of matrix metalloproteinase-2/9 in MDA-MB-435 human breast cancer cells. Exp Biol Med (Maywood) 2008; 233: 1013-1020. https://doi.org/10.3181/0801-RM-7

[19] GAO R, LI L, SHANG B, ZHAO C, SHENG W et al. A Gelatinases-targeting scFv-based Fusion Protein Shows Enhanced Antitumour Activity with Endostar against Hepatoma. Basic Clin Pharmacol Toxicol 2015; 117: 105-116. https://doi.org/10.1111/bcpt.12379

[20] XU X, MAO W, CHEN Q, ZHUANG Q, WANG L et al. Endostar, a modified recombinant human endostatin, suppresses angiogenesis through inhibition of Wnt/beta-catenin signaling pathway. PLoS One 2014; 9: e107463. https://doi. org/10.1371/journal.pone.0107463 
[21] YU ZW, JU YH, YANG CL, YU HB, LUO Q et al. Antitumor effect of recombinant human endostatin combined with cisplatin on rats with transplanted Lewis lung cancer. Asian Pac J Trop Med 2015; 8: 664-667. https://doi.org/10.1016/j. apjtm.2015.07.010

[22] LIN TC, CHEN ST, HUANG MC, HUANG J, HSU CL et al. GALNT6 expression enhances aggressive phenotypes of ovarian cancer cells by regulating EGFR activity. Oncotarget 2017; 8: 42588-42601. https://doi.org/10.18632/oncotarget.16585

[23] CHEN Q, YANG Z, CHEN X, SHU L, QU W. Peptide P7 inhibits the bFGF-stimulated proliferation and invasion of SKOV3 cells. Exp Ther Med 2019; 17: 3003-3008. https:// doi.org/10.3892/etm.2019.7309

[24] FAGIANI E, CHRISTOFORI G. Angiopoietins in angiogenesis. Cancer Lett 2013; 328: 18-26. https://doi.org/10.1016/j. canlet.2012.08.018

[25] SHEN M, XU Z, XU W, JIANG K, ZHANG F et al. Inhibition of ATM reverses EMT and decreases metastatic potential of cisplatin-resistant lung cancer cells through JAK/ STAT3/PD-L1 pathway. J Exp Clin Cancer Res 2019; 38: 149. https://doi.org/10.1186/s13046-019-1161-8

[26] LI P, HUANG T, ZOU Q, LIU D, WANG Y et al. FGFR2 Promotes Expression of PD-L1 in Colorectal Cancer via the JAK/STAT3 Signaling Pathway. J Immunol 2019; 202: 30653075. https://doi.org/10.4049/jimmunol.1801199

[27] PARDOLL DM. The blockade of immune checkpoints in cancer immunotherapy. Nat Rev Cancer 2012; 12: 252-264. https://doi.org/10.1038/nrc3239
[28] ABIKO K, MATSUMURA N, HAMANISHI J, HORIKAWA N, MURAKAMI $\mathrm{R}$ et al. IFN-gamma from lymphocytes induces PD-L1 expression and promotes progression of ovarian cancer. Br J Cancer 2015; 112: 1501-1509. https:// doi.org/10.1038/bjc.2015.101

[29] SAINI U, NAIDU S, ELNAGGAR AC, BID HK, WALLBILLICH JJ et al. Elevated STAT3 expression in ovarian cancer ascites promotes invasion and metastasis: a potential therapeutic target. Oncogene 2017; 36: 168-181. https://doi. org/10.1038/onc.2016.197

[30] FUJITA Y, YAGISHITA S, HAGIWARA K, YOSHIOKA $\mathrm{Y}$, KOSAKA $\mathrm{N}$ et al. The clinical relevance of the miR-197/ CKS1B/STAT3-mediated PD-L1 network in chemoresistant non-small-cell lung cancer. Mol Ther 2015; 23: 717-727. https://doi.org/10.1038/mt.2015.10

[31] LIU JF, DENG WW, CHEN L, LI YC, WU L et al. Inhibition of JAK2/STAT3 reduces tumor-induced angiogenesis and myeloid-derived suppressor cells in head and neck cancer. Mol Carcinog 2018; 57: 429-439. https://doi.org/10.1002/ mc. 22767

[32] LENGYEL E. Ovarian cancer development and metastasis. Am J Pathol 2010; 177: 1053-1064. https://doi.org/10.2353/ ajpath.2010.100105

[33] NAORA H, MONTELL DJ. Ovarian cancer metastasis: integrating insights from disparate model organisms. Nat Rev Cancer 2005; 5: 355-366. https://doi.org/10.1038/nrc1611

[34] PRADEEP S, KIM SW, WU SY, NISHIMURA M, CHALUVALLY-RAGHAVAN $\mathrm{P}$ et al. Hematogenous metastasis of ovarian cancer: rethinking mode of spread. Cancer Cell 2014; 26: 77-91. https://doi.org/10.1016/j.ccr.2014.05.002 